\title{
Analysis of Buffering Process of Control Rod Hydraulic Absorber
}

\author{
Jishi Bao \\ Institute of Nuclear and New Energy Technology, \\ Tsinghua University \\ Email: jishi0987@gmail.com
}

\section{INTRODUCTION}

Control Rod Hydraulic Drive Mechanism(CRHDM) is a newly invented built-in control rod drive technology. Hydraulic absorber is the key part of CRHDM. It is used to cushion control rod when the rod scrams to prevent the control rod from being deformed or damaged. It overcomes the operational instability of oil absorber caused by the change of fluid property, adapts to the nuclear reactor working environment using water as coolant and moderator, and solves the buffering problem of built-in control rod driving mechanism.

2. Analysis of Buffering Process and Model Application

As is shown in Fig.1, the control rod hydraulic absorber is comprised of a piston rod, disc spring, hydraulic cylinder, outflow holes and base.

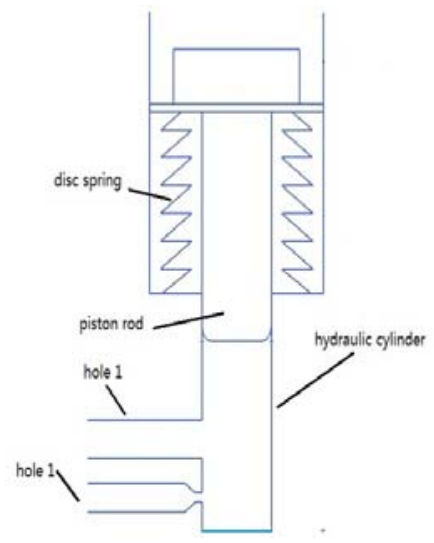

Fig.1 Schematic of Control rod hydraulic absorber

After control rod hits on the top of piston rod of hydraulic absorber. Control rod and piston rod will move down together compressing disc spring and pushing water in the hydraulic cylinder to flow out of two holes and the annular gap between the piston rod and the cylinder sidewall. Thus, some impact energy is converted into potential energy of disc spring, others converted into kinetic energy of water,

\section{Benke Qin \\ Hanliang Bo}

Institute of Nuclear and New Energy Technology, Tsinghua University, Email: qinbk@mail.tsinghua.edu.cn

and a very small part transformed into internal energy of water.

Flow resistance of hydraulic absorber is very important in determining the performance of hydraulic absorber. ANSYS CFX is used to simulate the flow field at different displacements of plunger piston to get the flow resistance coefficient of the hydraulic cylinder.

Based on the structure and working principle of hydraulic absorber, theoretical model is established which consists of continuity equation, flow resistance equation and dynamical equation. The model is solved by Euler forward difference method ${ }^{[1]}$ to obtain the time history of some key parameters.

With the help of theoretical model of buffering process, we can get the structure optimization direction by changing the key parameters of hydraulic absorber. In this paper the influence of piston rod diameter and elasticity of disc spring is analyzed.

\section{CONCLUSIONS}

(1) Flow resistance of hydraulic absorber flow holes is calculated using ANSYS CFX.

(2) Theoretical model of buffering is established.

(3) The maximum acceleration calculated using dynamic model is less than the allowed maximum acceleration.

(4) There exists an optimal value of disc spring elasticity, which can result in the smallest value of the maximum buffering acceleration..

\section{REFERENCES}

[1] Qingyang Li, Zhi Guan, Fengshan Bai, 2000. Principle of numerical calculation. Tsinghua University Press. Beijing 


\section{Analysis of Buffering Process of Control Rod Hydraulic Absorber}

\author{
Jishi Bao \\ Institute of Nuclear and New Energy Technology, \\ Tsinghua University, \\ Key Laboratory of Advanced Reactor \\ Engineering and Safety of the Ministry of \\ Education \\ Beijing, 100084 China \\ Email: jishi0987@gmail.com
}

\author{
Benke Qin \\ Hanliang Bo \\ Institute of Nuclear and New Energy Technology, \\ Tsinghua University, \\ Key Laboratory of Advanced Reactor \\ Engineering and Safety of the Ministry of \\ Education \\ Beijing, 100084 China \\ Email: qinbk@mail.tsinghua.edu.cn
}

\begin{abstract}
Control Rod Hydraulic Drive Mechanism(CRHDM) is a newly invented build-in control rod drive mechanism. Hydraulic absorber is the key part of this mechanism, and is used to cushion the control rod when the rod scrams. Thus, it prevents the control rod from being deformed and damaged. In this paper dynamics program ANSYS CFX is used to calculate all kinds of flow conditions in hydraulic absorber to obtain its hydraulic characteristics. Based on the flow resistance coefficients obtained from the simulation results, fluid mass and momentum equations were developed to get the trend of pressure change in the hydraulic cylinder and the displacement of the piston rod during the buffering process of the control rod. The results obtained in this paper indicate that the hydraulic absorber meets the design requirement. The work in this paper will be helpful for the design and optimization of the control rod hydraulic absorber.
\end{abstract}

Key Words: hydraulic absorber, ANSYS CFX, flow resistance coefficients, buffer model, numerical solution

\section{Introduction}

Control Rod Hydraulic Drive Mechanism(CRHDM) is a newly invented built-in control rod drive technology. It is developed with the features of the hydraulic control rod driving system invented by Tsinghua University, and the advantages of the magnetic jack in pressurized water reactor(PWR). Hydraulic absorber is the key part of
CRHDM. It is used to cushion control rod when the rod scrams to prevent the control rod from being deformed and damaged.

Hydraulic absorber converts impact energy of control rod falling down to the kinetic energy of water and the potential energy of disc spring through hydraulic absorber cylinder and disc spring. It overcomes the operational instability of oil absorber caused by the change of fluid property, adapts to the nuclear reactor working environment using water as coolant and moderator, and solves the buffering problem of built-in control rod driving mechanism. The pressure in hydraulic cylinder and the outflow during the buffering process of control rod are the key parameters for the design and optimization of hydraulic absorber. Because of the structural characteristics of control rod hydraulic drive mechanism, it is impossible to layout monitoring points of pressure and flow rate in hydraulic cylinder. In this paper Computational Fluid Dynamics(CFD) software ANSYS CFX is used to simulate the flow field and hydraulic characteristics of hydraulic absorber at different displacements of plunger piston to get the flow resistance coefficient of the hydraulic cylinder. Then, a dynamic model was established based on the structure and working principle of the hydraulic absorber and the buffering process calculation is carried out to get the key parameters. This theoretical model provides the basis for design and optimization of hydraulic absorber and also expands the 
application of the related experimental results.

\section{Structure and Working Principle of Hydraulic}

\section{Absorber}

As is shown in Fig.1, the control rod hydraulic absorber is comprised of a piston rod, disc spring, hydraulic cylinder, outflow holes and base. The whole working process of hydraulic absorber can be divided into two parts: the process of buffering and the process of resetting.

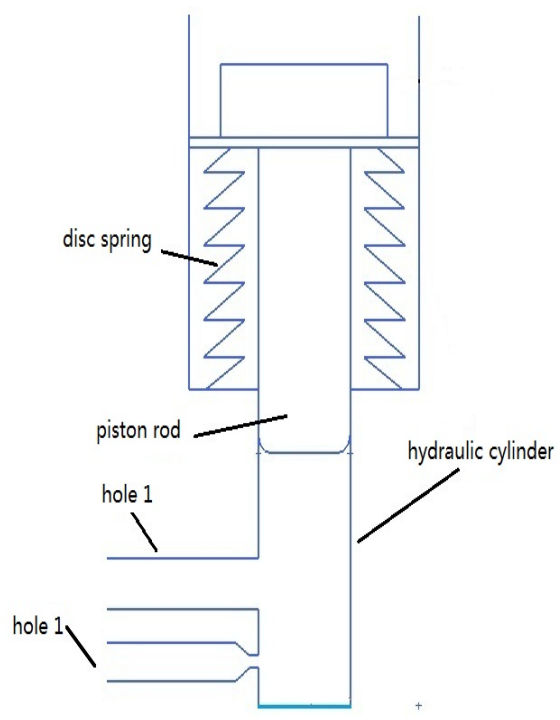

Fig.1 Schematic of Control rod hydraulic absorber

When nuclear reactor shuts down, control rod falls rapidly from the top of the reactor pressure vessel, and its bottom hits on the top of piston rod of hydraulic absorber. As the mass of piston rod is much less than that of the control rod, control rod and piston rod will move down together compressing disc spring after they strike and compress water in hydraulic cylinder to flow out of two holes and the annular gap between the piston rod and the cylinder sidewall. Because of the damping effect of flow holes and the compressibility of water, water in hydraulic absorber gives piston rod an upward force. This force combined with resilience of disc spring makes velocity of control rod and piston rod decrease. Some impact energy is converted into potential energy of disc spring, others converted into kinetic energy of water, and a very small part converted into internal energy of water. After the buffering process, the resetting process begins through the disc spring.

\section{Numerical Calculation of Flow Resistance of Hydraulic Absorber}

Considering the structural characteristics of hydraulic absorber, some unimportant parts are ignored and the simplified geometric model is shown in Fig.2.

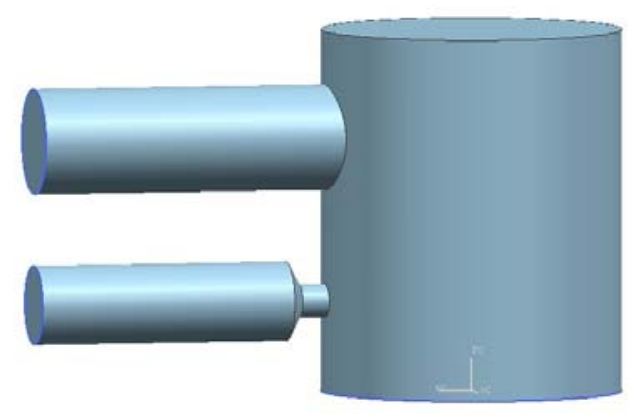

Fig. 2 The flow channel of hydraulic absorber

The damping effect of flow holes in hydraulic absorber is achieved by flow resistance when water flows out of hydraulic cylinder. During the buffering process, the piston rod blocks flow holes in the sidewall gradually. The flow resistance changes significantly with the downward movement of piston $\operatorname{rod}^{[1]}$. In numerical calculation several key locations are shown in Fig.3 where the labeled horizontal line represents the position of the bottom of piston rod. The flow resistance coefficients of hydraulic cylinder with piston rod at these positions were obtained by CFD software ANSYS CFX.

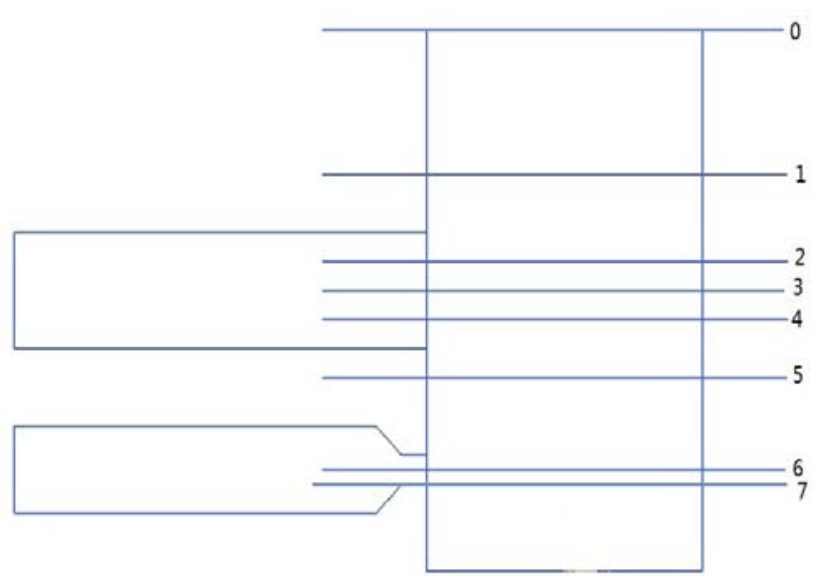

Fig.3. Key positions of the piston rod for CFX calculation

CFX Preprocessing including modeling, meshing, boundary condition loading, and etc. were carried out, and the mesh was refined at sensitive areas. Water of $250^{\circ} \mathrm{C}$ was chosen and reference pressure was set at 5MPa. The flow state was set to be stationary flow. Heat transfer model was set to a total energy model. $k-\varepsilon$ model was chosen as the turbulence model. A scalable wall function was adopted. Boundary conditions were as follows: inlet velocity was 
$5 \mathrm{~m} / \mathrm{s}$. Outlet relative pressure was $0 \mathrm{~Pa}$. Take the case that the bottom of piston rod is above two holes (line 1 in Fig.3) as an example. The velocity vector and pressure contour are shown in Fig.4. In addition, calculation result shows that temperature of water rises very slightly, about 0.15 degrees Celsius. So the energy converted to water internal energy is very small.

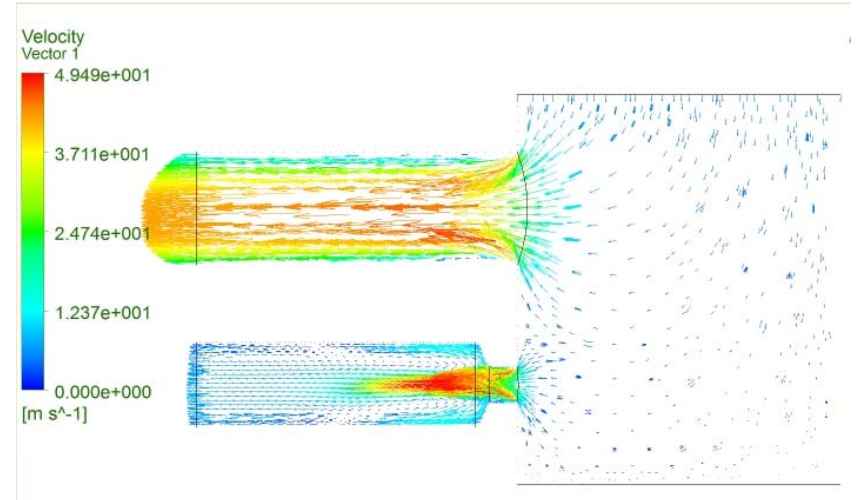

(a) Velocity vector

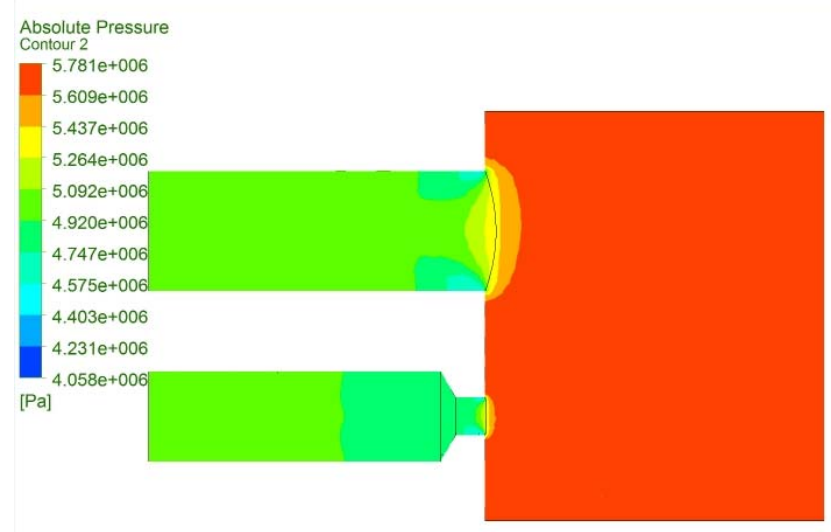

(b) pressure contour

Fig.4 Flow field in the hydraulic cylinder

Table1 1. Flow resistance coefficients of hydraulic cylinder with piston rod at different positions.

(“Inf” represents infinite)

\begin{tabular}{|c|c|c|}
\hline $\begin{array}{l}\text { Location of } \\
\text { piston rod }\end{array}$ & $\begin{array}{l}\text { Resistance } \\
\text { coefficient } \\
\text { upper hole }\end{array} \quad \begin{array}{l}\text { Resistance } \\
\text { coefficient of } \\
\text { bottom hole }\end{array}$ \\
\hline 0 & 1.45 & 37.8 \\
\hline 1 & 1.45 & 40.0 \\
\hline 2 & 1.86 & 100.0 \\
\hline 3 & 4.84 & 106.1 \\
\hline 4 & 22.5 & 107.9 \\
\hline 5 & Inf & 110.0 \\
\hline 6 & Inf & 162.6 \\
\hline 7 & Inf & Inf \\
\hline
\end{tabular}

Flow resistance coefficient ${ }^{[2]}$ is defined as:

$$
\zeta_{p o r}=\frac{2 \Delta p_{p o r}}{\rho v_{p o r}^{2}}
$$

Where,

$\zeta_{\text {por }}$-resistance coefficient of hole;

$\Delta p_{\text {por }}$-differential pressure of hole;

$v_{\text {por }}$ - velocity of flow though hole;

$\rho$-density of flow;

Flow resistance coefficients of hydraulic cylinder calculated by ANSYS CFX are listed in Table 1. In order to make computation easier, flow coefficient of cushion hole is used in place of resistance coefficient, which is defined as:

$$
A_{p o r} v_{p o r}=A_{p o r} \sqrt{\frac{2 \Delta p_{p o r}}{\rho \zeta_{p o r}}}=A_{p o r} \sqrt{\frac{2 \Delta p_{p o r}}{\rho}} \sqrt{\frac{1}{\zeta_{p o r}}}
$$

Where, $A_{p o r}$ - area of hole;

And flow coefficient is:

$$
C_{p o r}=\sqrt{\frac{1}{\zeta_{p o r}}}
$$

Where, $C_{\text {por }}$-flow coefficient;

Thus, the right hand side of equation (2) can be written as:

$$
C_{p o r} A_{p o r} \sqrt{\frac{2 \Delta p_{p o r}}{\rho}}
$$

Replacing resistance coefficient with flow coefficient, we can get flow coefficient that varies with the displacement of piston rod (Fig.5). Flow coefficient is the key parameter for mass conservation equation during the process of buffering. 


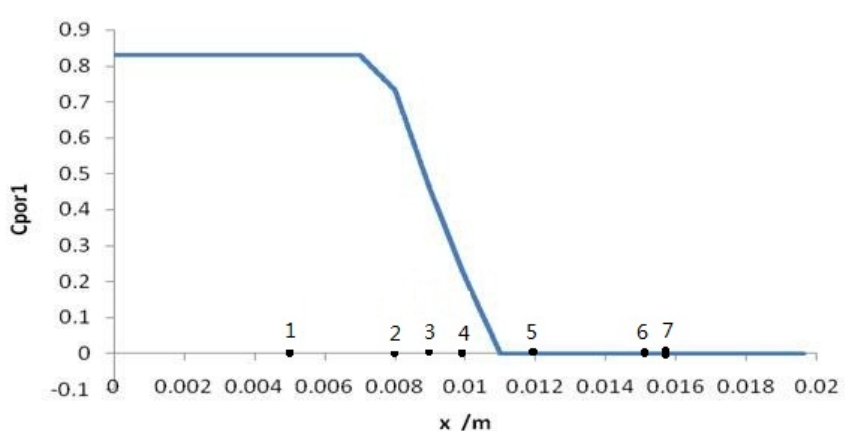

(a) Flow coefficient of upper hole vs. the displacement of piston rod

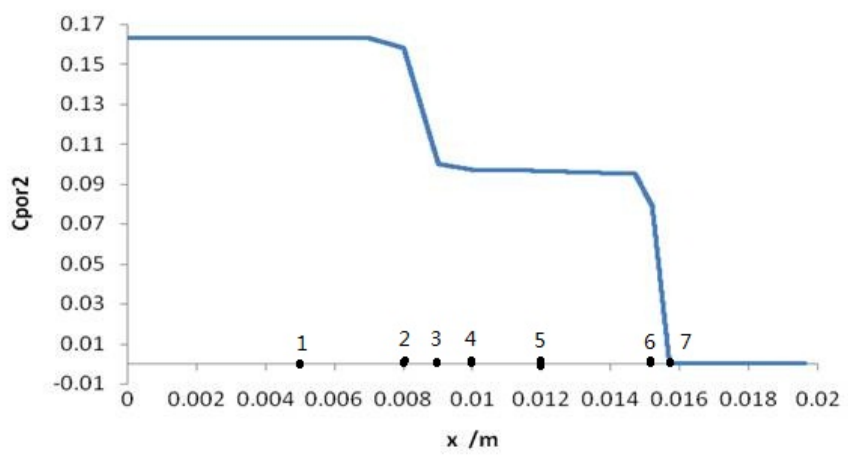

(b) Flow coefficient of bottom hole vs. the displacement of piston rod

Fig.5. Relation between flow coefficient of cushion holes and the displacement of piston rod

As is shown in Fig.5, in the beginning of buffering, the flow coefficient of holes keeps almost unchanged. When the piston rod reaches certain location, flow coefficient of upper hole begins to decrease rapidly to 0 . Flow coefficient of bottom hole also decreases, but not to 0 . As piston rod moves down further, flow coefficient of bottom hole remains unchanged at first, later decreases rapidly to 0 . The change of flow coefficient of flow holes can be explained as follows: When piston rod doesn't block cushion holes, the pressure-flow rate relationship of holes is unchanged. Thus, flow resistance coefficient keeps constant. That is to say, flow coefficient is unchanged. When the cushion holes in sidewall begin to be blocked, the outflow area decreases. So resistance coefficient increases, flow coefficient decreases. Flow of upper hole can intensify the mixing of water in hydraulic cylinder, making water flow out of bottom hole more easily. When upper hole is blocked completely, the mixing intensification effect vanishes, bottom hole outflow rate decreases, that is, resistance increases, flow coefficient decreases. When the two cushion holes are all blocked completely by the piston rod, water can not flow out of the holes and the flow resistance becomes infinite, flow coefficient is 0 .

\section{Theoretical Model of Buffering}

The theoretical model of buffering consists of continuity equation and momentum equation. Because the time duration of the buffering process is short, pressure in hydraulic cylinder will be very high, compressibility of water should be considered.

\subsection{Continuity Equation}

In the process of buffering most of water inside the hydraulic cylinder flows out of two holes, and the residual water leaks out though the gap between piston rod and hydraulic cylinder (Fig.6).

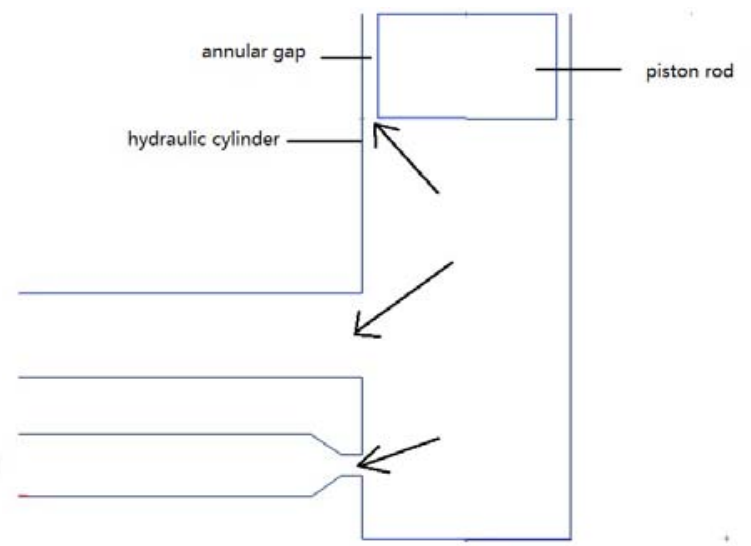

Fig.6 Fluid leakage channel

Take water in hydraulic cylinder as the research object. The volume repelled by piston rod is $\pi R^{2} v_{\text {pis }}$. The flow though the upper hole ${ }^{[3]}$ is $C_{\text {por } 1} A_{\text {por1 } 1} \sqrt{\frac{2 \Delta p_{\text {por } 1}}{\rho}}$. The flow though the bottom hole is $C_{\text {por } 2} A_{\text {por } 2} \sqrt{\frac{2 \Delta p_{\text {por } 2}}{\rho}}$. The flow though the annular gap ${ }^{[4]}$ is $\frac{\pi D_{p i s} \delta^{3} \Delta p}{12 \mu\left(L_{0}+x_{p i s}\right)}$. The compressed volume caused by pressure in hydraulic cylinder $^{[5]}$ is $\frac{A_{p i s}\left(L-x_{p i s}\right)}{K} \frac{d p}{d t}$.

Thus, according to flow mechanism of buffering, continuity equation can be written as: 


$$
\begin{aligned}
& \pi R^{2} v_{p i s}=C_{p o r 1} A_{p o r 1} \sqrt{\frac{2 \Delta p_{p o r}}{\rho}}+C_{p o r 2} A_{p o r 2} \sqrt{\frac{2 \Delta p_{p o r} 2}{\rho}} \\
& +\frac{\pi D_{p i s} \delta^{3} \Delta p}{12 \mu\left(L_{0}+x_{p i s}\right)}+\frac{A_{p i s}\left(L-x_{p i s}\right)}{K} \frac{d p}{d t}
\end{aligned}
$$

Where, $R$ - radius of hydraulic cylinder; $\quad v_{\text {pis }}-$ velocity of piston rod;

$A_{\text {por1 }}$ - area of upper hole;

$A_{\text {por } 2}$ - area of bottom hole;

$\Delta p_{\text {por1 }}$ - differential pressure of upper hole;

$\Delta p_{\text {por2 }}$ - differential pressure of bottom hole; $\Delta p$ differential pressure of hydraulic cylinder;

$C_{\text {por1 }}$ - flow coefficient of upper hole; $C_{\text {por } 2}-$ flow coefficient of bottom hole;

$D_{\text {pis }}$ - diameter of piston rod;

$\delta$ - gap between piston rod and hydraulic cylinder;

$\mu$ - dynamic viscosity of water;

$K$ - modulus of water;

$p$-pressure of hydraulic cylinder;

$L_{0}$ - the initial length between the bottom of piston rod and the top of hydraulic cylinder;

$A_{\text {pis }}$ - cross area of piston rod;

$L$ — the height of hydraulic cylinder ;

$x_{\text {pis }}$ - the displacement of piston rod.

The acceleration of the pressure of hydraulic cylinder can be derived from Equation (5):

$$
\begin{aligned}
& \frac{d p}{d t}=\frac{K}{A_{p i s}\left(L-x_{p i s}\right)}\left(\pi R^{2} v_{p i s}-C_{p o r 1} A_{p o r 1} \sqrt{\frac{2 \Delta p_{p o r}}{\rho}}\right. \\
& \left.-C_{p o r 2} A_{p o r 2} \sqrt{\frac{2 \Delta p_{p o r} 2}{\rho}}-\frac{\pi D_{p i s} \delta^{3} \Delta p}{12 \mu\left(L_{0}+x_{p i s}\right)}\right)
\end{aligned}
$$

The result obtained by ANSYS CFX indicates that the differential pressure of upper hole is equal to that of bottom hole. That is to say: $\Delta p_{\text {por } 1}=\Delta p_{\text {por } 2}=\Delta p$.

Since $\frac{d p}{d t}=\frac{d\left(p_{0}+\Delta p\right)}{d t}=\frac{d \Delta p}{d t}$, where, $p_{0}$ - reference pressure;

Eq. (6) can be written as:

$$
\begin{aligned}
& \frac{d \Delta p}{d t}=\frac{K}{A_{p i s}\left(L-x_{p i s}\right)}\left(\pi R^{2} v_{p i s}-C_{p o r 1} A_{p o r 1} \sqrt{\frac{2 \Delta p}{\rho}}\right. \\
& \left.-C_{p o r 2} A_{p o r} \sqrt{\frac{2 \Delta p}{\rho}}-\frac{\pi D_{p i s} \delta^{3} \Delta p}{12 \mu\left(L_{0}+X_{p i s}\right)}\right)
\end{aligned}
$$

\subsection{Dynamic Model of Control Rod and Piston} Rod

Control rod and piston rod move down together after they strike with each other. Consider them as a whole, the force analysis during buffering process is shown in Fig.7.

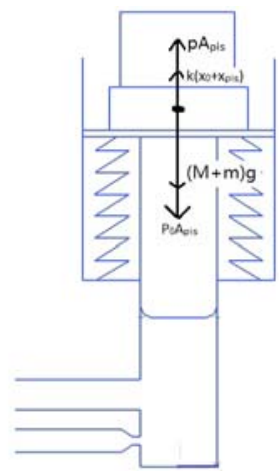

Fig.7 Force analysis of control rod and piston rod during buffering

Thus, momentum equation can be given:

$$
(M+m) \frac{d v_{p i s}}{d t}=(M+m) g-k\left(x_{0}+x_{p i s}\right)+p_{0} A_{p i s}-p A_{p i s}
$$

Where, $M-$ mass of control rod;

$m$ - mass of piston rod;

$k$ - elasticity of disc spring;

$x_{0}$ - the initial compressed length of disc spring.

From which we obtain the velocity :

$$
\frac{d v_{p i s}}{d t}=g+\frac{-k\left(x_{0}+x_{p i s}\right)+p_{0} A_{p i s}-p A_{p i s}}{M+m}
$$

And it is obvious that: 


$$
\frac{d x_{p i s}}{d t}=v_{p i s}
$$

Thus, Eq. (7), (9) and (10) can be united to form the whole theoretical model of buffering process. Though the model, the change of $\Delta p, v_{\text {pis }}, x_{\text {pis }}$ can be obtained.

\section{Model Application and Result Analysis}

Solving the theoretical model of buffering with Euler forward difference method ${ }^{[6]}$, we can get the key parameters including velocity, displacement, acceleration, and etc.. According to the force analysis of control rod, its dynamic equation during buffering is:

$$
M \frac{d v_{p i s}}{d t}=M g-F
$$

which can be rearranged as: $F=M g-M \frac{d v_{p i s}}{d t}$.

Thus we can get the cushion force as a function of time.

Initial condition: $\Delta p=0 \mathrm{~Pa}, v_{p i s}=5 \mathrm{~m} / \mathrm{s}, \quad x_{p i s}=0$.

Time step: $0.00001 \mathrm{~s}$

Table 2. simulating parameters

\begin{tabular}{|c|c|l|l|c|c|c|}
\hline parameter & value & unit & & parameter & value & unit \\
\hline$D_{\text {pis }}$ & 10.0 & $\mathrm{~mm}$ & & $\mu$ & $\begin{array}{c}1.0 \mathrm{e}- \\
4\end{array}$ & $\mathrm{~N} \cdot \mathrm{s} / \mathrm{m}^{2}$ \\
\hline$d_{\text {por1 }}$ & 4.0 & $\mathrm{~mm}$ & & $\rho$ & 800.0 & $\mathrm{~kg} / \mathrm{m}^{3}$ \\
\hline$L$ & 19.5 & $\mathrm{~mm}$ & & $K$ & $2.0 \mathrm{e} 9$ & $\mathrm{~Pa}$ \\
\hline$L_{0}$ & 6.0 & $\mathrm{~mm}$ & & $M$ & 30 & $\mathrm{~kg}$ \\
\hline
\end{tabular}

Fig.8-Fig.11 show the time history of key parameters during buffering process.

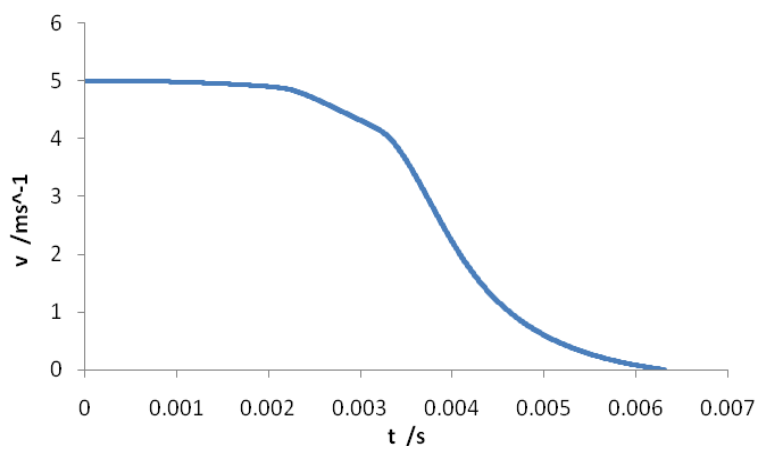

Fig.8 piston rod velocity

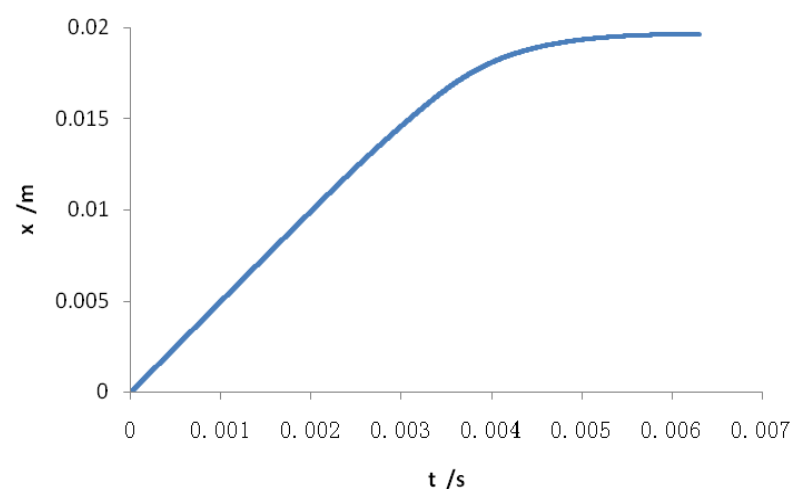

Fig.9 curve of piston rod

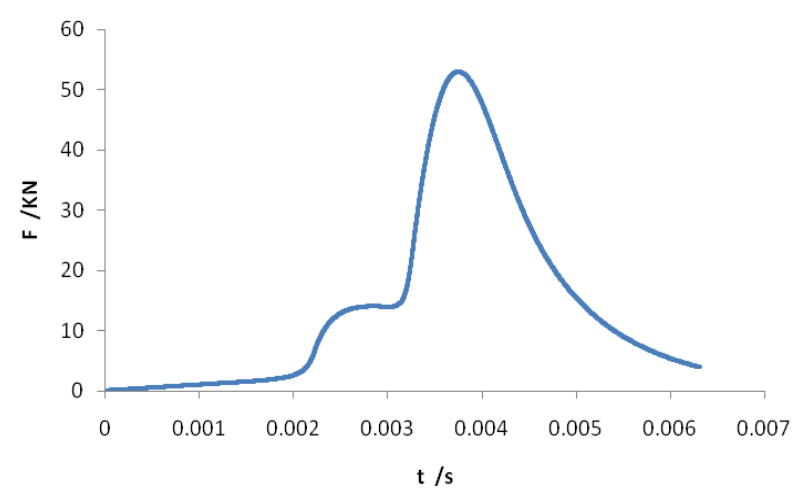

Fig.10 hydraulic absorber buffering force

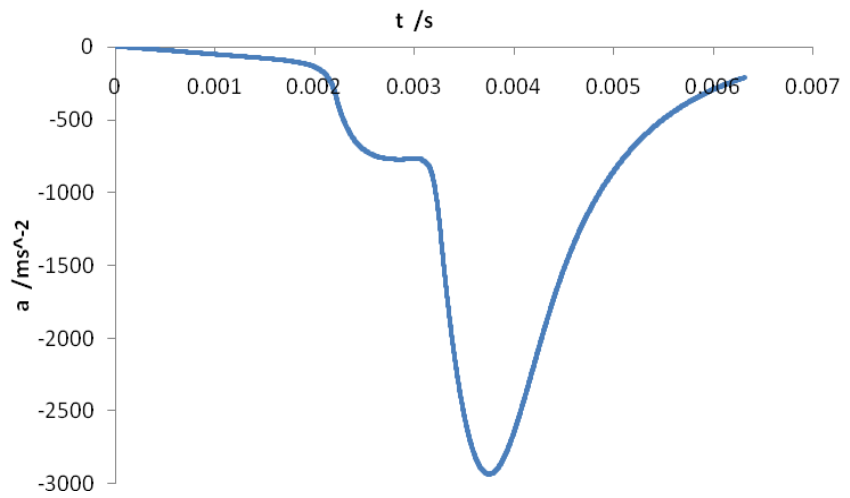

Fig.11 piston rod accelaration

The curves of velocity and displacement during buffering process are shown in Fig.8 and Fig.9. We can see that the velocity decreases slowly at first,then dropped rapidly, and at last it slowly declines to 0 . The displacement of piston rod didn't reach the distance limit that hydraulic absorber allows. Cylinder-bottom-hitting event doesn’t happen.

Fig.10 and Fig.11 show buffering force and accelaration vs. time. We can see that, in the beginning the accelaration is small, and the accelaration grows gradually as the displacement increases. Then there is a sharp increase of accelaration to the peak. This conforms to the geometry of hydraulic absorber. When 
piston rod begins to move down, water flows out of two holes and annular gap. When piston rod begins to shelter upper hole, its flow area decreases, flow resistance increases, pressure inside hydraulic cylinder increases, accelaration of piston rod increases. When upper hole is blocked completely water can only flow out from bottom hole and annular gap. Flow resistance increases sharply. Differential pressure of the hydraulic cylinder increases, therefore buffering force and accelaration increase. After piston rod shelters bottom hole completely, water can only flow out from annular gap. Thus, differential pressure of hydraulic cylinder and accelaration of piston rod increase sharply. Then, as high pressure forces water to flow out from annular gap, pressure of hydraulic cylinder decreases. Accelaration of piston rod decreases from rapidly to slowly. At last, velocity of piston rod decreases to 0 . Two inflection points in the curve of Fig.11 correspond to the position of two holes respectively. we can see from Fig.11 that the maximum accelaration appears at the postion that two holes are blocked.

Considering the structural characteristics and material of control rod, the buffering process of control rod have been simulated using Finite Element Analysis, and the acceleration limit has been obtained. As long as the maximum acceleration is less than this acceleration limit, control rod will not be deformed and destructed. As we can see from Fig.11, the maximum acceleration is $290 \mathrm{~g}$, which is well less than the acceleration limit of control rod. So the design parameters of hydraulic absorber meet engineering design requirements.

\section{Model Parameter Analysis}

We take the maximum acceleration as the evaluation standard. On the basis of theoretical model of buffering, we can get the direction for structural optimization by changing the key parameters of hydraulic absorber. These structural parameters include the diameter of piston rod, elasticity of disc spring, diameter and position of two flow holes in the sidewall of hydraulic cylinder. In this paper the influence of piston rod diameter and elasticity of disc spring will be analyzed.

Fig.12 shows the change of maximum acceleration with diameter of piston rod. The curve trend is decided by two factors. As the diameter of piston rod increases, more water needs to be drained under the same displacement of piston rod. whereas the flow area of holes is unchanged, excess water will be pressed out from holes by growing differential pressure between the inside and outside of the hydraulic cylinder caused by the compression of water. On the other hand, annular gap flow resistance increases with the increase of piston rod diameter. In the meanwhile, with the growing piston rod diameter, the pressure of hydraulic cylinder increases, and the displacement of piston rod becomes shorter. It is the above two factors that influence the maximum acceleration as diameter of piston rod changes(Fig.13). As the curve sequence number in Fig.13 grows, diameter of piston rod grows. We can see that when diameter of piston rod is small, annular gap has greater impact on maximum acceleration. As diameter increases, bottom hole becomes dominant. When the diameter of piston rod exceeds certain value the influence of the upper hole becomes the major part.

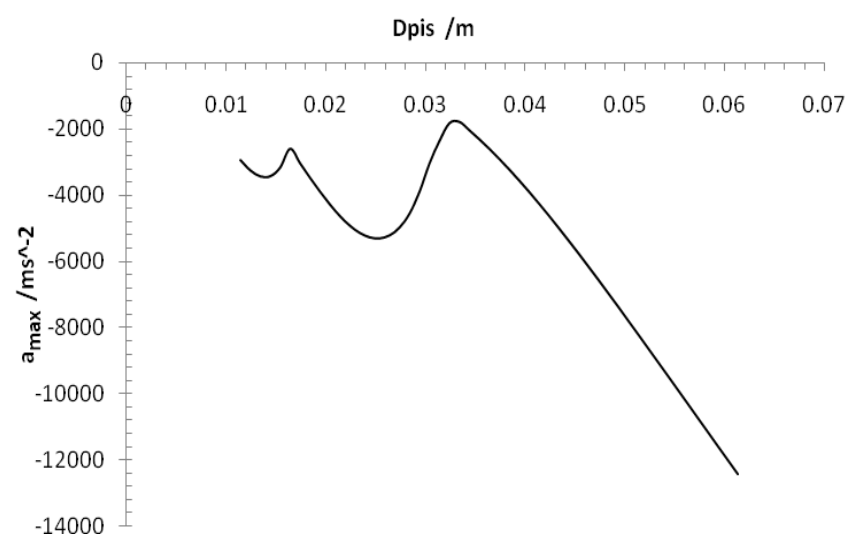

Fig.12 Relationship curve of buffering maximum acceleration and piston rod diameter

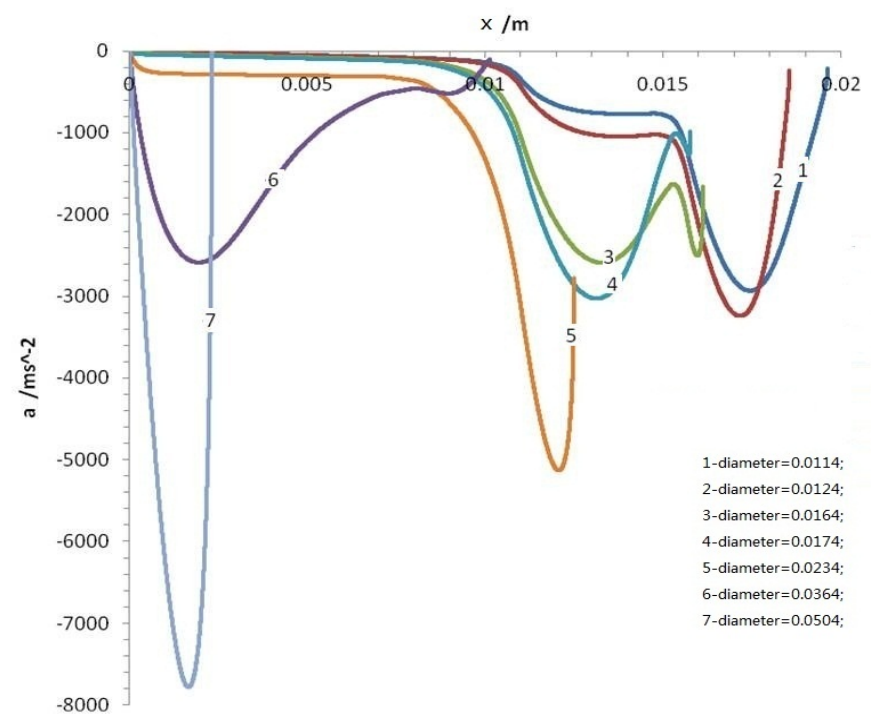

Fig.13 Buffering acceleration vs. displacement of different diameter of piston rod

Copyright (C) 2011 by JSME 
Fig.14 shows the relationship between maximum acceleration and elasticity of disc spring. We can see that as elasticity of disc spring increases, maximum acceleration increases to a maximum value at first. Then, it decreases. This can be explained as follows: when elasticity of disc spring is small, if piston rod shelters two holes completely, the control rod is slowed down by annular gap and compression of water. As elasticity of disc spring grows, energy stored in disc spring grows too, and the displacement of piston rod becomes shorter. The proportion of energy dissipated by annular gap and compression of water becomes less. The maximum acceleration decreases. When elasticity of disc spring reaches a certain value, if it grows further, force of disc spring grows rapidly. Disc spring becomes the main buffering component. The maximum acceleration will increase along with elasticity of disc spring.

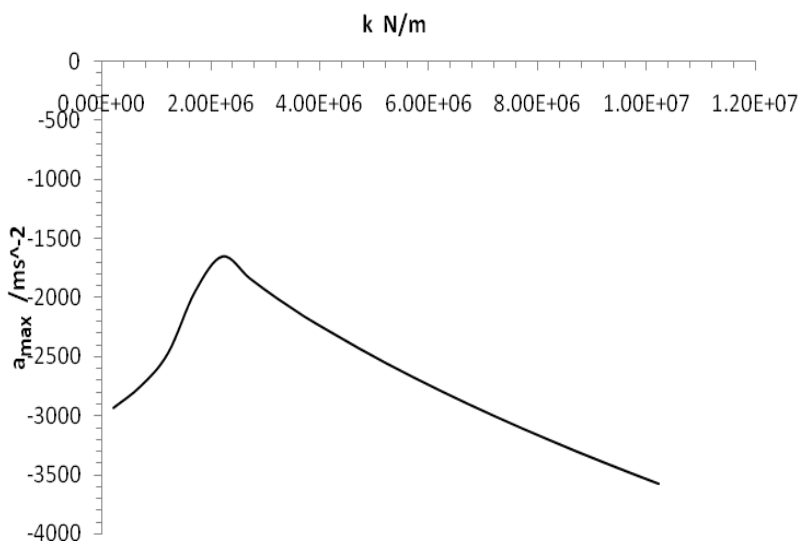

Fig.14 maximum acceleration changing with elasticity of disc spring

\section{Conclusion}

1) In this paper the mechanism of buffering of control rod hydraulic absorber is analyzed. Dynamic model of buffering is established. It is consisted of continuity equation and momentum equation.

2) Computational Fluid Dynamics software ANSYS CFX is used to calculate flow resistance of holes when piston rod moves down to different positions. Calculation results obtained is used in dynamic model of buffering to get the dynamic process of velocity, displacement, force of buffering, acceleration during the process of control rod buffering.

3) The calculation result accords with the mechanism of hydraulic absorber. The maximum acceleration in the process of buffering is less than acceleration limit of control rod. So the hydraulic absorber meets design requirement.
4) The influence of internal diameter of hydraulic cylinder to buffering performance is decided by flow out of the cushion holes and flow resistance of annular gap. These two factors lead to the valley values of the acceleration curve.

5) There exists an optimal value of disc spring elasticity, which can result in the smallest value of the maximum buffering acceleration compared to other values of elasticity of disc spring.

\section{References}

[1] Shao Hua, Xuening Yang, 1985. Practical Handbook of Fluid Resistance. National Defence Industry Press. Beijing.

[2] Zhaoshun Zhang, Guixiang Cui, 2006. Fluid Mechanics. Tsinghua University Press. Beijing.

[3] Pengfei Hao, Xiwen Zhang, Feng He, 2003.Sudy on Dnamic Caracteristics of small Hdraulic Bmper. Chinese Journal of Mechanical Engineering. 39(3), March, pp, 155-158.

[4] Lei Zhang, Yu Wang, Zhaodong Wen, Shaohua Shi, 2009. Simulation Research on Theory of the Passive Hydraulic Buffer and Its Working Process. Machine Tool and Hydraulics. 37(11), November, pp, 84-86.

[5]Yiming Zhang, 1994. Study on the Designing Parameters of Hydraulic Buffer. Journal of East China Institute of Metallurgy. 11(3), July, pp,54-58.

[6] Qingyang Li, Zhi Guan, Fengshan Bai, 2000. Principle of numerical calculation. Tsinghua University Press. Beijing. 